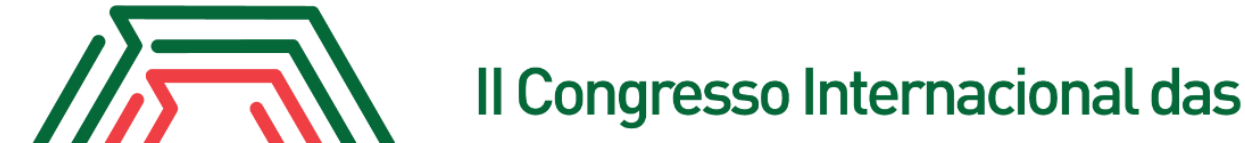 Ciências Agrárias COINTER - PDVAgro 2017
}

\section{LÂMINAS DE IRRIGAÇÃO E NITROGÊNIO NO CRESCIMENTO DE DUAS CULTIVARES DE BATATA DOCE NO SERTÃO PARAIBANO}

\author{
Apresentação: Comunicação Oral \\ SÉFORA CORDEIRO SUASSUNA ${ }^{1}$; DANILA LIMA DE ARAÚJO²; DANIEL DA SILVA \\ FERREIRA $^{1}$;EVANDRO FRANKLIN DE MESQUITA ${ }^{3}$; LOURIVAL FERREIRA \\ CAVALCANTE ${ }^{4}$
}

\begin{abstract}
Resumo
A horticultura é responsável por mais de $70 \%$ da produção familiar local, destacando a ascensão da batata doce que se insere entre as quatro hortaliças mais consumidas em Catolé do Rocha, PB. Apesar da relevante expressividade da horticultura, pelo rápido retorno do capital investido, ocupação da mão-de-obra e obtenção de renda da propriedade no período da estiagem, os produtores da mesorregião de Catolé do Rocha, há quase 10 anos veem convivendo com as baixas produtividades, em função, da baixa pluviosidade, a constante irregularidade das chuvas associado a um manejo nem sempre adequado em termos de adubação e irrigação, na tentativa de elevar a produtividade da região. Nesse sentido, objetivou-se avaliar o crescimento de duas variedades de batata doce variedade Granfina (casca branca) e campina (casca roxa) sob irrigação e adubação nitrogenada. Os tratamentos foram em parcelas subdivididas distribuídas em blocos casualizados com 3 repetições, usando o esquema fatorial $2 \mathrm{~A} \times(2 \mathrm{C} \times 5 \mathrm{~N})$, referentes a duas lâminas de irrigação (100\% ETc e $50 \%$ ETc), duas cultivares de batata-doce Granfina (Casca branca) e Campina (Casca roxa), e cinco doses de nitrogênio correspondentes a $0,25,50,75$ e $100 \%$ da dose de $120 \mathrm{~kg} \mathrm{ha}^{-1}$ de $\mathrm{N}$ na forma sulfato de amônio $(20 \% \mathrm{~N}), 20 \%$ acima da dose de $100 \mathrm{~kg} \mathrm{ha}^{-1}$ utilizada por Alves et al. (2009), com um total de 60 parcelas. As variáveis analisadas de crescimento foram diâmetro caulinar, número de folhas e comprimento do ramo principal. Diante do exposto, o nitrogênio influenciou positivamente o crescimento de batata doce de casca branca (Granfina) e casca roxa (Campina). A redução de $100 \%$ para $50 \%$ evapotranspiração da cultura -ETC- afetou negativamente o crescimento das cultivares de batata doce em condições de clima semiárido.
\end{abstract}

Palavras Chaves: Ipomea batatas, regime hidrico, adubação organomineral.

\section{Introdução}

A microrregião de Catolé do Rocha, pertencente à mesorregião do Alto Sertão paraibano, formada pelos municípios de Belém do Brejo do Cruz, Bom Sucesso, Brejo do Cruz, Brejo dos Santos, Catolé do Rocha, Jericó, Lagoa, Mato Grosso, Riacho dos Cavalos, São Bento e São José do Brejo do Cruz, apresenta uma grande diversidade dos seus sistemas produtivos com viabilidade

\footnotetext{
${ }^{1}$ Alunos do Curso de Licenciatura em Ciências Agrárias, Universidade Estadual da Paraíba, e-mail: sefora.cordeiro@hotmail.com e-mail: danielzsilva3456@gmail.com .

${ }^{2}$ Aluna do Programade Pós graduação em Agronomia/UFPB/CampusIII/Areia-PB,e-mail: danilalimaraujo@hotmail.com

${ }^{3}$ Professor orientador da Universidade Estadual da Paraíba, Campus IV - e-mail: elmesquita4@uepb.edu.br

${ }^{4}$ Professor coorientador da Universidade Federal da Paraíba, Areia-PB, e-mail: lofeca1946@yahoo.com.br
} 
ambiental para o desenvolvimento de novas atividades agropecuárias, destacando-se a produção de plantas hortícolas. Nesse contexto, a cultura da batata doce (Ipomea batatas) pode ser inserida devido sua adequada adaptação às condições do clima semiárido, associado a textura dos solos, na maioria, textura franca arenosa, arejados e de boa permeabilidade, além da expressiva importância da respectiva cultura na produção hortícola da agricultura familiar local.

Dentre os estados nordestinos, a Paraíba é o maior produtor e o quarto maior produtor brasileiro de batata-doce explorada predominantemente em regime de agricultura familiar. Apesar do quarto lugar entre os estados mais produtivos da cultura a produtividade paraibana de $6,4 \mathrm{t} \mathrm{ha}^{-1}$ é muito baixa e a nacional com rendimento de 11,04 t ha ${ }^{-1}$ é baixa (IBGE, 2017). Essa situação é devida, em geral, a diminuição volumétrica dos mananciais de superfície e subterrâneos, em função dos insuficientes e mal distribuídos índices pluviométricos, elevadas temperatura do ar e do solo, resultando em evaporação média de $10 \mathrm{~mm}$ dia. no período da estiagem .Outra séria inconveniência é a carência de tecnologia que possibilite a convivência no semiárido, informações e conhecimentos, principalmente, com relação à fertilização organomineral e o regime hídrico adequado. Conforme (SANTOS et al. 2006), esses problemas como verificado na região de Areia$\mathrm{PB}$, provocam perda de produtividade e de receita, desestimulam os produtores locais e contribuem para o decréscimo da área plantada, como registrado na microrregião de Catolé do Rocha-PB, aumentando o êxodo rural e causando problemas sociais de desemprego.

Nas áreas semiáridas, além das limitações expostas, o baixo teor de matéria orgânica do solo constitui num sério problema para agricultura irrigada e não irrigada no Nordeste brasileiro, especificamente no alto sertão paraibano por ser considerado um estresse abiótico que limita o crescimento e a produção das culturas (CAVALCANTE et al., 2010). A matéria orgânica melhora a retenção água do solo e após sua mineralização fornece nutrientes às plantas, fato confirmado por Oliveira et (2013) que alcançaram 16,7 $\mathrm{t} \mathrm{ha}^{-1}$ raízes, utilizando 29,0 $\mathrm{t} \mathrm{ha}^{-1}$ de esterco caprino. No mesmo raciocínio, Santos et al. (2006) observaram maiores produções total e comercial de raízes, cuja valores foram 18,5 e 14,2 t ha-1, obtidas, respectivamente, com 32 e $30 \mathrm{t} \mathrm{ha}^{-1}$ de esterco bovino. Os referidos autores constataram incrementos de 9,85 e $8,62 \mathrm{t} \mathrm{ha}^{-1}$ de raízes, respectivamente, que corresponderam a ganhos de, respectivamente, 112 e $154 \%$ em relação às produções obtidas na ausência de adubação com esterco bovino.

Diante do exposto, objetivou-se avaliar o avaliar o crescimento de duas variedades de batata doce variedade Granfina (casca branca) e campina (casca roxa) sob irrigação e adubação nitrogenada.

\section{Fundamentação Teórica}


O semiárido do Nordeste brasileiro com uma extensão territorial estimada de $982.583,3 \mathrm{~km}^{2}$ onde reside uma população de 22.598.318 habitantes, superior as das regiões Norte e Centro-Oeste, e representando aproximadamente $12 \%$ da população brasileira (IBGE, 2017). A acelerada exigência por alimentos em uma região com condições adversas à agricultura de sequeiro associada ao ritmo bem mais lento da produção de alimentos, a baixa tolerância da maior parte das plantas economicamente viáveis à escassez água e deficiência nitrogenada, acarretando perda de rendimento e da qualidade de produção a medida que aumento o stress hídrico, e a necessidade pela expansão de áreas para produção agrícola evidenciam a exigência de adoção de tecnologias que viabilizem o uso de águas de da irrigação e adubação organomineral, inclusive no cultivo da batata doce.

Uma das alternativas à produção de culturas em condições de clima semiárido é a utilização de técnicas de irrigação ou insumos orgânicos que atenuem os efeitos degenerativos da escassez hídrica no sertão paraibano. Nesse contexto, se insere a matéria orgânica que quando aplicada em doses adequadas exerce efeitos positivos como condicionador de solo, melhorando as propriedades físicas, químicas e biológicas disponibilizando nutrientes às plantas (SILVA et al., 2012).

$\mathrm{O}$ nitrogênio $(\mathrm{N})$ é o segundo nutriente mineral mais exigido pelas hortaliças que produzem tubérculos, em termos de quantidade, a exemplo da batata doce. Porém, o excesso da adubação nitrogenada pode ser prejudicial à cultura pelo crescimento vegetativo desequilibrado. No Brasil, dados referentes adubação orgânica para melhorar a eficiência da adubação química e extração de nutrientes pela batata doce são escassos. No entanto, (Echer et al. 2009) constataram que as raízes tuberosas representam a grande fonte de exportação de nutrientes, inclusive a batata doce. Para uma produtividade de $6.290 \mathrm{~kg} \mathrm{ha}^{-1}$ de massa seca, os macronutrientes mais extraídos foram $\mathrm{N}$ (129 $\left.\mathrm{kg} \mathrm{ha}^{-1}\right)$ e o $\mathrm{K}\left(81 \mathrm{~kg} \mathrm{ha}^{-1}\right)$ indicativo de que boa parte dos nutrientes extraídos está contida nas raízes tuberosas.

\section{Metodologia}

O trabalho foi desenvolvido entre de junho/2017 a outubro/2017, instalado na área experimental do setor agroecologia, pertencente ao Centro de Ciências Humanas e Agrárias da Universidade Estadual da Paraíba, Câmpus IV, Catolé do Rocha-PB. O município está inserido na região semiárida do Alto sertão paraibano, situado pelos pontos das coordenadas geográficas: latitude $6^{\circ} 20^{\prime} 38^{\prime \prime}$ Sul, longitude $37^{0} 44^{\prime} 48^{\prime \prime}$ a Oeste do Meridiano de Greenwich e a uma altitude de $275 \mathrm{~m}$. O clima é quente e seco caracterizado por temperatura média de $28^{\circ} \mathrm{C}$, máximas e mínimas médias de 35 e $23^{\circ} \mathrm{C}$,respectivamente. A pluviosidade histórica média nos últimos cinco oscila em torno de $500 \mathrm{~mm}$, dos quais mais de $65 \%$ são precipitados nos três primeiros meses do período das chuvas; a umidade relativa média do ar nos meses da estiagem é inferior a $50 \%$ (ESTAÇÃO 


\section{AGROMETEOROLOGIA, 2017).}

O solo foi classificado como NEOSSOLO FLÚVICO Eutrófico (Embrapa, 2013), apresentou, nos primeiros $20 \mathrm{~cm}$ de profundidade, 661, 213 e $126 \mathrm{~g} \mathrm{~kg}^{-1} \mathrm{de}$ areia, silte, argila; densidade do solo e de partículas, 1,51 e $2,76 \mathrm{~g} \mathrm{~cm}^{-3}$, respectivamente, com porosidade total de 0,45 $\mathrm{m}^{3} \mathrm{~m}^{-3}$. Os valores da umidade na capacidade de campo, ponto de murchamento permanente e água disponível foram 23,52; 7,35 e 16,17\%, respectivamente. Quanto à caracterização química, o solo na mesma profundidade apresentou, conforme as metodologias de Embrapa (2011), pH = 6,7; $\mathrm{P}$ e $\mathrm{K}^{+}=458$ e $16,19 \mathrm{mg} \mathrm{dm}{ }^{-3} ; \mathrm{Na}^{+}=0,10 \mathrm{cmol}_{\mathrm{c}} \mathrm{dm}^{-3} ; \mathrm{Ca}^{2+}=1,49 \mathrm{cmol}_{\mathrm{c}} \mathrm{dm}^{-3} ; \mathrm{Mg}^{2+}=0,54 \mathrm{cmol}_{\mathrm{c}} \mathrm{dm}^{-3}$; $\mathrm{Al}=0,0 \mathrm{cmol}_{\mathrm{c}} \mathrm{dm}^{-3} ; \mathrm{H}+\mathrm{Al}=0,0 \mathrm{cmol}_{\mathrm{c}} \mathrm{dm}^{-3} \mathrm{e} \mathrm{MO}=1,15 \%$.

Os tratamentos foram distribuídos em parcelas subdivididas distribuídas em blocos casualizados com quatro repetições usando o esquema fatorial $2 \mathrm{~A} \times(2 \mathrm{C} \times 4 \mathrm{~N})$, referentes a duas lâminas de irrigação (100\% ETc e 60\% ETc), duas cultivares de batata doce: branca (Granfina) e a roxa (Campina) e quatro doses de nitrogênio correspondentes a 25, 50, 75 e 100\% da dose de 120 $\mathrm{kg} \mathrm{ha}^{-1}$ de N na forma de ureia $(45 \% \mathrm{~N}), 20 \%$ acima da dose de $100 \mathrm{~kg} \mathrm{ha}^{-1}$ utilizada por Alves et al. (2009), em solo com 3,3\% de matéria orgânica.

Cada tratamento ou subparcela foi constituída por três leiras preparadas manualmente com $4 \mathrm{~m}$ de comprimento, 0,40 $\mathrm{m}$ de largura e 0,35 $\mathrm{m}$ de altura, com volume de $0,56 \mathrm{~m}^{3}\left(560 \mathrm{dm}^{3}\right)$ espaçadas de $1 \mathrm{~m}$, para estudo da parcela central. Cada subparcela deve ser separada da outra na mesma linha de $0,5 \mathrm{~m}$. Dessa forma cada parcela deve ter comprimento de $18 \mathrm{~m}$. O esterco bovino em cada solo será aplicado na base da leira com $10 \mathrm{~cm}$ de altura, conforme a expressão abaixo de Bertino et al. (2015).

$\mathrm{QEB}=\left(40 \mathrm{~g} \mathrm{~kg}^{-1}-\mathrm{TMOSP}\right) \mathrm{x}$ VL $\mathrm{x}$ ds $\mathrm{x}$ UE/TMOEB

Em que:

QEB = Massa de esterco bovino descontada a umidade (g);

TMOSP = Teor de matéria orgânica que o solo possui;

$\mathrm{VL}=$ Volume do leirão $\left(\mathrm{dm}^{3}\right)$ :

$\mathrm{ds}=$ Densidade do solo $\left(\mathrm{g} \mathrm{dm}^{-3}\right)$;

$\mathrm{UE}=$ Umidade do esterco bovino $(\%)$;

TMOEB = Teor de matéria orgânica existente no esterco bovino.

Cada dose de $\mathrm{N}$ foi fornecida em três aplicações de 1/3 no preparo dos leilões, aos 30 e 60 dias após o plantio das ramas sementes de batata doce (Ipomea batatas), variedade Granfina e Campina.

A irrigação das plantas foi realizada diariamente pelo método de irrigação localizada, adotando o sistema por gotejamento com vazão do gotejador $(q)=1,6 \mathrm{~L} \mathrm{~h}^{-1}$, de acordo com a evapotranspiração 
da cultura-ETc $\left(\mathrm{mm} \mathrm{d}^{-1}\right)$. O cálculo foi feito com base na evapotranspiração de referência (ETo, $\mathrm{mm} \mathrm{d}^{-1}$ ), estimada pelo tanque Classe $A$ e corrigida pelo Kc da cultura de acordo com o estágio de desenvolvimento da planta, obtendo o uso consultivo (Uc) considerando o percentual de área molhada $(\mathrm{P})=100 \%$. Com isso, para fins do cálculo da lâmina de irrigação líquida diária (LLD = ETc), incluindo a fração 6/7 de irrigação do domingo, teve-se LLD = Uc x P/100 $\left(\mathrm{mm} \mathrm{d}^{-1}\right)$; a partir deste valor, determinou-se as lâminas aplicadas correspondentes a 50 e 100\% LLD que foram aplicadas diariamente e se usava o tempo de aplicação como forma de redução do volume de água $\left(\mathrm{CE}_{\text {água }}=1,1 \mathrm{dS} \mathrm{m}^{-1}\right)$, isto é, na lâminas de $100 \%$ ETc serão duas fitas por e na lâmina $50 \%$ ETc será uma fita por canteiro. As variáveis atribuídas no experimento foram: coeficiente do tanque classe $\mathrm{A}(\mathrm{Kp})=0,75$; coeficiente de cultivo variável de acordo com o estágio da cultura $(\mathrm{Kc})$ $=$ serão 0,$4 ; 0,8$ e 1,0 e 1,4 nos primeiros 30 dias após o plantio (DAP), dos 30 aos 60 DAP, dos 60 aos 90 DAP e dos 90 até 130 DAP (DOORENBOS \& KASSAM, 1994; DOORENBOS \& PRUIT, 1997). A diferenciação das lâminas será feita aos 15 dias após o plantio (DAP).

As variáveis analisadas foram o número de folhas obtido pela contagem do total de folhas de uma planta por parcela principal aos 45 DAP (Dias após o plantio). A medição do ramo principal foi mensurada a $2 \mathrm{~cm}$ acima da superfície do solo através de um paquímetro digital utilizando mm como unidade. O número de ramos secundários foi obtido através de contagem.

\section{Resultados e Discussão}

De acordo com a análise de variância (Tabela 1), ocorreu efeito significativo para a variáveis de crescimento a $1 \%$ de probabilidade com relação às cultivares de batata doce. Já para as variáveis número de folhas e ramos secundários observou efeito significativo para os fatores lâminas de irrigação e doses de nitrogênio, respectivamente. Exceto o numero de folhas, o diâmetro do ramo principal e o número de ramos secundários responderam significativamente aos efeitos da interação entre as lâminas de irrigação, cultivares e doses de nitrogênio.

Tabela 1. Resumo da análise de variância para o número de folhas por planta (NFP), diâmetro do ramo principal (DRP) e Números de ramos secundários (NRS), em função de lâminas de irrigação, cultivares e doses de nitrogênio no cultivo da batata doce, aos 45 dias após a plantio, Catolé do Rocha-PB, UEPB, 2017.

\begin{tabular}{|c|c|c|c|c|}
\hline \multirow[b]{2}{*}{ Causas da Variação } & \multirow[b]{2}{*}{ GL } & \multicolumn{3}{|c|}{ Significância dos quadrados médios } \\
\hline & & $\begin{array}{c}\text { Folhas } \\
\text { (NFP) }\end{array}$ & $\begin{array}{l}\text { Diâmetro } \\
\text { (DRP) }\end{array}$ & $\begin{array}{c}\text { Ramos secundário } \\
\text { (NRS) }\end{array}$ \\
\hline Bloco & 2 & ns & $\mathrm{ns}$ & $\mathrm{Ns}$ \\
\hline Lâminas (A) & 1 & $* *$ & ns & Ns \\
\hline Cultivares (B) & 1 & $* *$ & $* *$ & $* *$ \\
\hline Nitrogênio (C) & 4 & ns & ns & $* *$ \\
\hline$A * B$ & 1 & ns & ns & Ns \\
\hline $\mathrm{A}^{*} \mathrm{C}$ & 4 & $*$ & ns & $* *$ \\
\hline
\end{tabular}




\begin{tabular}{lcccc}
$\mathrm{B} * \mathrm{C}$ & 4 & $*$ & $\mathrm{~ns}$ & $* *$ \\
$\mathrm{~A} * \mathrm{~B} * \mathrm{C}$ & 4 & $\mathrm{~ns}$ & $* *$ & $* *$ \\
Resíduo & 38 & 2183,88 & 1,65 & 25,10 \\
\hline \multicolumn{1}{c}{$\mathrm{CV}(\%)$} & & 16,24 & 14,66 & 20,48 \\
\hline$* *$
\end{tabular}

** - P $\leq 0,01$, pelo teste $\mathrm{F} ;{ }^{*}$ - Significativo a $5 \%$ de probabilidade, pelo teste $\mathrm{F}$; ns - Não significativo, CV coeficiente de variação.

As doses crescentes de nitrogênio influenciaram no número de folhas da batata doce casca branca (Granfina) e roxa (Campina) (Figura 1 A e B), quando irrigada sem déficit hídrico no solo (100\% ETc), onde foram observados que a maior dose $120 \mathrm{~kg} \mathrm{ha}^{-1}$ promoveu os maiores números de folhas por planta na ordem 349 e 415 folhas ( planta $^{-1}$ ) com superioridade de $19 \%$ da cultivar roxa, possivelmente, devido a características intrínsecas. Já os tratamentos submetidos ao stress hídrico no solo (50\% ETc), os dados não de ajustaram a nenhum modelo matemático com média de 259 e 203 folhas ( planta $^{-1}$ ). Esses resultados evidenciam que essa hortaliça responde ao fornecimento da adubação nitrogenada, fato confirmado por Oliveira et al. (2015), que observaram incrementos de produção da batata doce, cultivar rainha branca, em função da adubação de nitrogenada.

Provavelmente, o nível a adubação nitrogenada, juntamente com os nutrientes contidos na matéria orgânica do solo, elevada a $3 \%$ e no solo, supriu de forma equilibrada a batata-doce, favorecendo o crescimento vegetativo.

Constatou-se que a lâmina de irrigação (100\% da ETc) foi mais eficiente no Número de folhas das cultivares de batata doce comparado às plantas irrigadas com a lâmina de $50 \%$ da ETc. Concordando Doorenbos e Kassam (2000), quando a necessidade hídrica da planta é plenamente satisfeita, existe uma relação direta entre a evapotranspiração e o crescimento, ou seja, evapotranspiração máxima corresponde a crescimento máximo. No entanto, Lima et al. (2006), quando há uma restrição hídrica ocorre, também, redução do crescimento, devido à redução na tensão matricial da água no solo, provocando queda no consumo hídrico com reflexos negativos na diâmetro caulinar das plantas.

Figura 1. Número de folhas por planta de cultivares de batata doce Granfina (A) e Campina (B), em função de doses de nitrogênio e lâminas de irrigação.
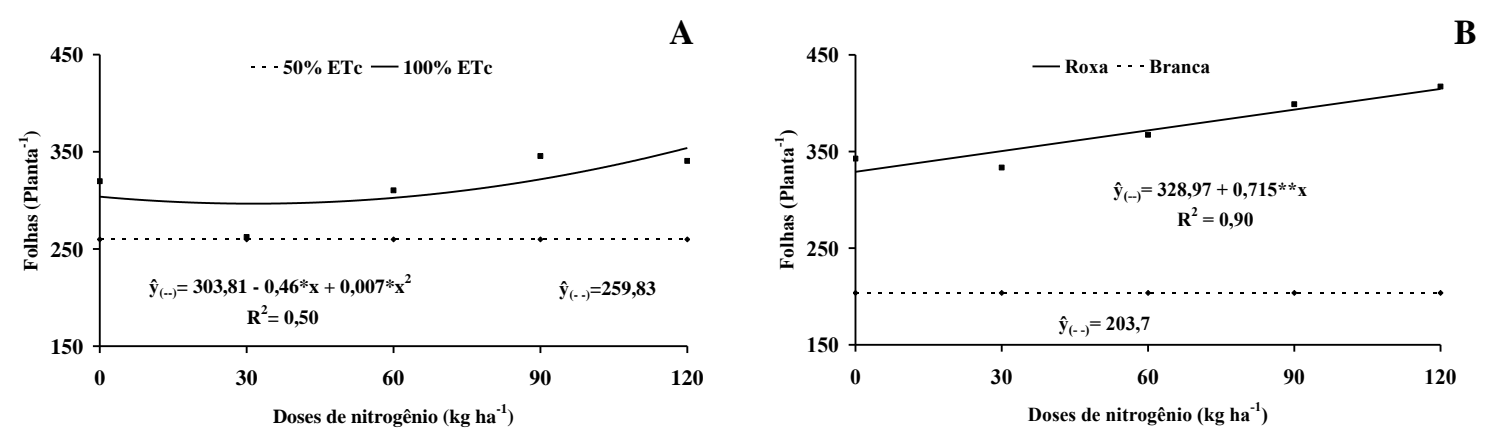
Com relação ao diâmetro do ramo principal das cultivares de batata doce, os dados relativos a doses de nitrogênio foram ajustados a um modelo quadrático, no qual as doses de (52,85 e 120 $\mathrm{kg} / \mathrm{ha})$ e (59 e $64 \mathrm{~kg} / \mathrm{ha})$ de nitrogênio em cobertura propiciou a maiores respostas, com (10,26 e $9,67 \mathrm{~mm})$ e $(9,47$ e $8,7 \mathrm{~mm})$, referentes aa cultivares Branca (Granfina) e roxa (Campina), submetidos aos regimes hídricos de $100 \%$ e $50 \%$ ETc, respectivamente. Os maiores valores do diâmetro da rama principal, formadas nos solos sem estresse hídrico associado o aumento da quantidade de nitrogênio ao solo pode estar ao parcelamento da adubação nitrogenada e o aumento do teor de matéria orgânica do solo apara 3\%, essencial, para um solo textura franca arenosa. Aplicação de nitrogênio promoveu o crescimento vegetativo das cultivares de batata doce, fato confirmado por Ferreira (2017), que observou o maior acúmulo de N nas raízes parte aérea da batata doce.

Independentemente da cultivar, observar maior diâmetro do ramo principal nas plantas formadas sem restrições hídricas em comparação àquelas formadas com déficit hídrico no solo. O déficit hídrico no solo causa redução em sua absorção e com isso, as células das plantas tem menor pressão de turgor, levando a menor expansão (TAIZ \& ZEIGER, 2013).

Figura 2. Diâmetro caulinar do ramo principal de cultivares de batata doce Granfina (A) e Campina (B), em função de doses de nitrogênio e lâminas de irrigação.

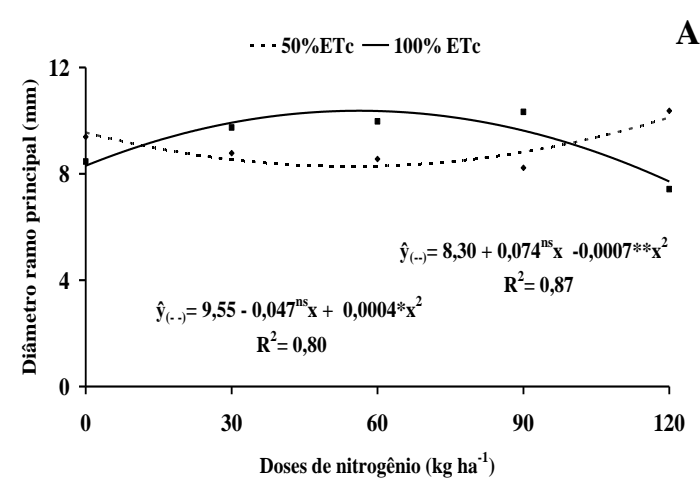

A

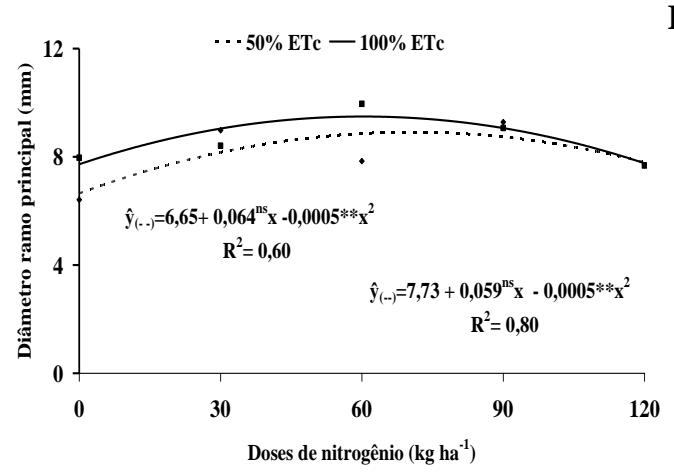

B

Para o número de ramos secundários das cultivares de batata houve ajuste das médias ao modelo de regressão do $2^{\circ}$ grau, onde observou-se aumentou incremento na dose de $\mathrm{N}$ aplicada. Conforme os resultados, houve relação diretamente proporcional entre o aumento no fornecimento de $\mathrm{N}$ e o numero de ramos secundários das cultivares, obtendo (21 e 19 ramos secundários) e (41 e 28 ramos secundários) para as batatas de casca branca (Granfina) e casca roxa (Campina), irrigadas com as lâminas de $100 \%$ e 50\% ETc, sendo obtidos teoricamente com as doses estimadas de (67,85 e 120 e $\left.\mathrm{kg} \mathrm{ha}^{-1}\right)$ e $\left(120 \mathrm{e} 70 \mathrm{~kg} \mathrm{ha}^{-1}\right)$, respectivamente, fato confirmado por Barcelos et al. (2006), que 
observaram que os fisiológicos e de produção da batata doce foi afetado pela parcelamento da dose de adubação do cobertura nitrogenada.

A redução da lâmina de irrigação de 100 para 50\% ETc resultou em diminuição dos ramos secundários, independentemente da cultivar, resultando em perdas de 10,52\% e 46,42\% para as batatas de casca branca e roxa, indicando que na fase de crescimento a batata casca roxa e susceptível ao stress hídrico do que a batata de casca branca. A superioridade da lâmina de 100\% é resposta do solo mais úmido, resultando em maior área de contato do íon $\mathrm{N}$ com a superfície das raízes. Esta situação está coerente com Prado (2008), ao afirmar que o movimento dos nutrientes no solo é maior sob condições hídricas adequadas, isto é, disponibilidade em nível suficiente às plantas.

Figura 3. Número de ramos secundários de cultivares de batata doce Granfina (A) e Campina (B), em função de doses de nitrogênio e lâminas de irrigação.
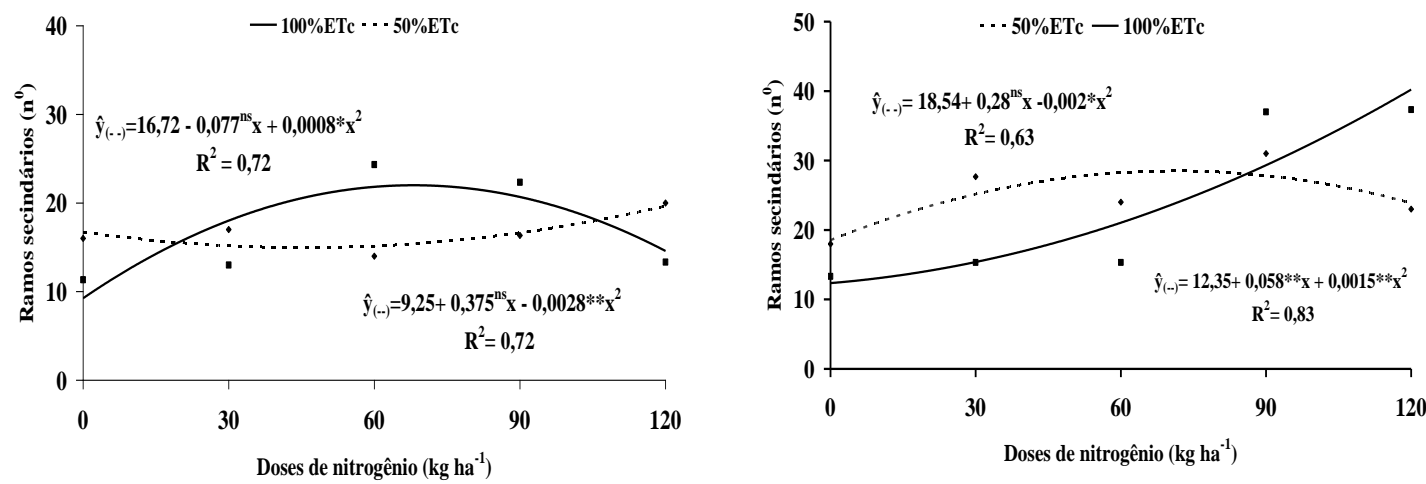

\section{Conclusões}

O nitrogênio influenciou positivamente o crescimento das cultivares de batata doce de casca branca (Granfina) e casca roxa (Campina).

A redução de $100 \%$ para $50 \%$ ETc afetou negativamente o crescimento das cultivares de batata doce.

\section{Referências}

ALVES, A.U.; OILIVEIRA, A.P.; ALVES, E.U.; OLIVEIRA, A.N.P.; CARDOSO, E.A.; MATOS, B.F. manejo da adubação nitrogenada para batata-doce: fontes e parcelamento de aplicação. Ciência agrotecnologia v. 33, n. 6, p. 1554-1559, 2009 
BERTINO, A. M. P.; MESQUITA, E. F.; SÁ, F. V. S.; CAVALCANTE, L. F.; FERREIRA, N. M.; PAIVA, E. P.; BRITO, M. E. B.; BERTINO, A. M. P. Growth and gás Exchange of okra under irrigation, organic fertilization and cover of soil. African Journal of Agricultural Research. V. 10 (40). PP. 3832-3839, 1, 2015.

CAVALCANTE, L.F.; DINIZ, A.A.; SANTOS, L.C.F.; REBEQUI, A.M.; NUNES, J.C.; BREHM, M.A.S. Teores foliares de macronutrientes em quiabeiro cultivado sob diferentes fontes e níveis de matéria orgânica. Semina: Ciências Agrárias, Londrina, v. 31, n. 1, p. 19-28, 2010.

DOORENBOS, J.; KASSAM, A. H. Efeito da água no rendimento das culturas. Tradução de GHEYI, H. R.; SOUSA. A. A.; DAMASCENO, F. A. V.; MEDEIROS, J. F. Campina Grande: UFPB. 1994. 306 p (Estudos FAO - Irrigação e Drenagem, 33)

DOORENBOS, J.; PRUITT, J. Necessidades hídricas das culturas. Tradução de GHEYI, H. R.;METRI, J. E. C.; DAMASCENO, F. A. V. Campina Grande: UFPB. 1997. 204 p (Estudos FAO - Irrigação e Drenagem, 24)

ECHER, F. R.; DOMINATO, J. C.; CRESTE, J. E.; SANTOS, D. H. Fertilização de cobertura com boro e potássio na nutrição e produtividade da batata-doce. Horticultura Brasileira. v. 27. n. 2, p. $171-175,2009$

EMBRAPA. Centro Nacional de Pesquisa de Solos. Sistema Brasileiro de Classificação de Solos. 3. ed. Brasília, DF: Embrapa Solos 2013.353p

IBGE. Instituto Brasileiro de Geografia e Estatística. 2017. Disponível em: http://www.ibge.com.br/home/estatistica/indicadores/agropecuaria/lspa/default.shtm. Acesso em 01 de maio de 2017.

LIMA, P. A.; MONTENEGRO, A. A. A.; LIRA JUNIOR, M. A.; SANTOS, F. X.; PEDROSA,E. M. R.; Efeito do manejo da irrigação com água moderadamente salina na produção de pimentão. Revista Brasileira de Ciências Agrárias, Recife, v.1, n.1, p.73-80, 2006.

OLIVEIRA, A.; GONDIM. P.C.; SILVA, O.P.R.; OLIVEIRA, A.N.P.; GONDIM, S.C.; SILVA, J.A. Produção e teor de amido da batata-doce em cultivo sob adubação com matéria orgânica. Revista Brasileira de Engenharia Agrícola e Ambiental, v.17, n.8, p.830-834, 2013 
RICHARDS, L. A. Diagnostico y rehabilitación de suelos salinos y sódicos. México: Departamento de Agricultura de los Estados Unidos de América, 1954. 174p. ( Manual de Agricultura,60).

SANTOS, J. F.; OLIVEIRA, A. P.; ALVES, A. U.;BRITO, C. H.; DORNELAS SANTOS, J. F.; C. S. M.; NÓBREGA, J. P.R. Produção de batata-doce adubada com esterco bovino em solo com baixo teor de matéria orgânica. Horticultura Brasileira, v. 24, n. 1, p. 103-106, 2006.

SIlvA, J. A.; OlIVEIRA, A. P.; AlVES, G. S.; CAVAlCANTE, L. F.; OLIVEIRA, A. N. P.; ARAÚJO, M. A. M. Rendimento do inhame adubado com esterco bovino e biofertilizante no solo e na folha. Revista Brasileira de Engenharia Agrícola e Ambiental, v. 16, n. 3, p. 253-257, 2012.

TAIZ, L.; ZEIGER, E. Fisiologia vegetal. 5.ed. Porto Alegre: Artmed, 918 p. 2013 